\title{
Diet and exercise in pregnancy
}

\author{
Lifestyle interventions are safe in pregnancy, and help control weight gain
}

\author{
Marian Knight NIHR professor of maternal and child population health ${ }^{1}$, Charlie Foster senior lecturer \\ for physical activity ${ }^{2}$
}

National Perinatal Epidemiology Unit, Nuffield Department of Population Health, University of Oxford, Oxford OX3 7LF, UK; ${ }^{2}$ Centre for Exercise, Nutrition \& Health Sciences, School for Policy Studies, Faculty of Social Sciences and Law, Bristol, UK

Both maternal obesity and excessive weight gain in pregnancy are known to be associated with pregnancy complications for mother and infant. ${ }^{1-3}$ Maternal obesity is also associated with longer term effects on childhood obesity ${ }^{2}$ and hence potential increases in non-communicable diseases. The prevalence of overweight and obesity is increasing in the maternity population in high resource countries. ${ }^{1}$ With the global nutrition transition, ${ }^{4}$ its impact will be more often observed in low and middle income settings. ${ }^{5}$ Information on trends in physical activity in pregnancy is less clear, although the data in the general population are well established-on a worldwide basis physical activity is not increasing. ${ }^{6}$ It is likely this stasis is also occurring in the maternity population; indeed it may be exacerbated by women's, families', and health professionals' concerns over the safety of physical activity during pregnancy. ${ }^{7}$

Several randomised controlled trials of diet and physical activity based interventions in pregnancy have therefore been conducted over recent years. Rogozinska and colleagues (doi:10.1136/bmj. j3119) conducted an individual participant data meta-analysis of these randomised trials, including data on more than 12000 women, and found a statistically significant mean decrease of $0.7 \mathrm{~kg}$ in gestational weight gain among the group of women who had received any diet or physical activity intervention, or both, during pregnancy. ${ }^{8}$ The authors found no differences in maternal or infant composite outcomes between the groups.

Many pregnancy complications are individually rare, or the effects of interventions on individuals are small. The challenge of interpreting research therefore is how to assess apparently positive effects of intervention when those effects are not statistically significant potentially as a result of inadequate sample size. Healthcare practitioners' scepticism about the value of interventions in pregnancy have been shown to be a barrier to implementation of weight management guidelines, ${ }^{9}$ and difficulties interpreting the evidence may play a part in this.

In the context of a recommended weight gain of $11.5-16 \mathrm{~kg}$ among women of normal weight, ${ }^{10}$ the importance to an individual of a $0.7 \mathrm{~kg}$ reduction may be unclear. However, guidelines have been developed for optimal pregnancy weight gain among different body mass index groups to improve maternal and child outcomes, ${ }^{10}$ and gestational weight gain above these recommended levels has been shown to be associated with an increased odds of macrosomia and caesarean delivery. ${ }^{11}$ Therefore across whole populations even a small reduction in gestational weight gain may have an important impact on rates of these outcomes.

Rogozinska and colleagues identified a statistically significant decrease in the caesarean section rate among women who had received any diet or physical activity intervention during pregnancy, with an estimated $9 \%$ decrease in odds. Notable, however, was the high caesarean birth rate- $34.8 \%$ in the intervention group and $37.7 \%$ in the control group. This highlights the importance of ongoing research into the underlying causes of increasing medical intervention in pregnancy ${ }^{12}$ but also raises our awareness of the possible effect of diet and physical activity on reducing rates.

The work of Rogozinska and colleagues provides little evidence of benefit of physical activity and diet interventions on pregnancy outcomes for either mother or infant. ${ }^{8}$ However, concerns are often expressed about the harms of diet, and particularly physical activity, interventions in pregnancy. This study provides reassuring information for women and healthcare practitioners about safety. The authors found no evidence of an increase in adverse pregnancy outcomes among women participating in dietary, physical activity, or mixed approach interventions (both diet and physical activity). The direction of the estimates of effect of both composite outcomes and the majority of the individual components of the composite outcomes favoured the intervention groups. We can therefore be confident in our advice to women that physical activity in pregnancy can be maintained.

The researchers note that at trial entry, $46 \%$ of women took no exercise or were sedentary, and perhaps this is where public health initiatives need to focus in the future. The physical activity interventions included in this meta-analysis were heterogeneous, with differing frequency, intensity, duration, and type of physical activity. The challenge remains for 
researchers to evaluate specific patterns of physical activity in pregnancy in both low and higher risk populations, and how these change with gestation.

For example, future studies could explore a possible role for strength and balance training in improving pregnancy outcomes, and consider whether pregnancy could be a window of opportunity to change physical activity patterns among women and their families in the longer term. In the context of evidence suggesting that lack of physical activity contributes almost $4 \%$ to the population risk of dementia, ${ }^{6}$ this is an opportunity we cannot afford to ignore.

Competing interests: We have read and understood the BMJ policy on declaration of interests and declare the following: MK has advised Amgen on clinical research in pregnant women with hypercholesterolaemia.

Provenance and peer review: Commissioned; not peer reviewed.

1 Poston L, Caleyachetty R, Cnattingius S, et al. Preconceptional and maternal obesity: epidemiology and health consequences. Lancet Diabetes Endocrinol 2016;358:1025-36. doi:10.1016/S2213-8587(16)30217-0. pmid:27743975.

2 Kominiarek MA, Peaceman AM. Gestational weight gain. Am J Obstet Gynecol 2017; published online first 24 May:S0002-9378(17)30651-8. doi:10.1016/j.ajog.2017.05. 040. pmid:28549978.
3 Knight M, Acosta C, Brocklehurst P, et al. Beyond maternal death: improving the quality of maternal care through national studies of 'near-miss' maternal morbidity. NIHR Journals Library, 2016.

4 Popkin BM, Adair LS, Ng SW. Global nutrition transition and the pandemic of obesity in developing countries. Nutr Rev 2012;358:3-21. doi:10.1111/j.1753-4887.2011.00456. x. pmid:22221213.

5 Hanson MA, Gluckman PD, Ma RC, Matzen P, Biesma RG. Early life opportunities for prevention of diabetes in low and middle income countries. BMC Public Health 2012;358:1025. doi:10.1186/1471-2458-12-1025. pmid:23176627.

6 Sallis JF, Bull F, Guthold R, et al. Lancet Physical Activity Series 2 Executive Committee. Progress in physical activity over the Olympic quadrennium. Lancet 2016;358:1325-36. doi:10.1016/S0140-6736(16)30581-5. pmid:27475270.

7 Currie S, Gray C, Shepherd A, McInnes RJ. Antenatal physical activity: a qualitative study exploring women's experiences and the acceptability of antenatal walking groups. BMC Pregnancy Childbirth 2016;358:182. doi:10.1186/s12884-016-0973-1. pmid:27448657.

8 The International Weight Management in Pregnancy (i-WIP) Collaborative Group. Effect of diet and physical activity based interventions in pregnancy on gestational weight gain and pregnancy outcomes: meta-analysis of individual participant data from randomised trials. BMJ 2017;358:j3119

9 Heslehurst N, Newham J, Maniatopoulos G, Fleetwood C, Robalino S, Rankin J. Implementation of pregnancy weight management and obesity guidelines: a meta-synthesis of healthcare professionals' barriers and facilitators using the Theoretical Domains Framework. Obes Rev 2014;358:462-86. doi:10.1111/obr.12160. pmid:24629076.

10 Rasmussen KM, Yaktine AL eds. Weight gain during pregnancy: reexamining the guidelines Washington, DC: The National Academies Press, 2009.

11 Goldstein RF, Abell SK, Ranasinha S, et al. Association of Gestational Weight Gain With Maternal and Infant Outcomes: A Systematic Review and Meta-analysis. JAMA 2017;358:2207-25. doi:10.1001/jama.2017.3635. pmid:28586887.

12 Betran AP, Torloni MR, Zhang JJ, Gülmezoglu AM. WHO Working Group on Caesarean Section. WHO Statement on Caesarean Section Rates. BJOG 2016;358:667-70. doi:10. 1111/1471-0528.13526. pmid:26681211.

Published by the BMJ Publishing Group Limited. For permission to use (where not already granted under a licence) please go to http://group.bmj.com/group/rights-licensing/ permissions 